\title{
Neuroinflammation is increased in the parietal cortex of atypical Alzheimer's disease
}

Baayla D. C. Boon 1,2*, Jeroen J. M. Hoozemans ${ }^{2}$, Boaz Lopuhaä², Kristel N. Eigenhuis², Philip Scheltens ${ }^{1}$, Wouter Kamphorst ${ }^{2}$, Annemieke J. M. Rozemuller ${ }^{2}$ and Femke H. Bouwman ${ }^{1}$

\begin{abstract}
Background: While most patients with Alzheimer's disease (AD) present with memory complaints, 30\% of patients with early disease onset present with non-amnestic symptoms. This atypical presentation is thought to be caused by a different spreading of neurofibrillary tangles (NFT) than originally proposed by Braak and Braak. Recent studies suggest a prominent role for neuroinflammation in the spreading of tau pathology.

Methods: We aimed to explore whether an atypical spreading of pathology in AD is associated with an atypical distribution of neuroinflammation. Typical and atypical AD cases were selected based on both NFT distribution and amnestic or non-amnestic clinical presentation. Immunohistochemistry was performed on the temporal pole and superior parietal lobe of 10 typical and 9 atypical AD cases. The presence of amyloid-beta ( $\mathrm{N}$-terminal; IC16), pTau (AT8), reactive astrocytes (GFAP), microglia (Iba1, CD68, and HLA-DP/DQ/DR), and complement factors (C1q, C3d, C4b, and (5b-9) was quantified by image analysis. Differences in lobar distribution patterns of immunoreactivity were statistically assessed using a linear mixed model.

Results: We found a temporal dominant distribution for amyloid-beta, GFAP, and Iba1 in both typical and atypical AD. Distribution of pTau, CD68, HLA-DP/DQ/DR, C3d, and C4b differed between AD variants. Typical AD cases showed a temporal dominant distribution of these markers, whereas atypical AD cases showed a parietal dominant distribution. Interestingly, when quantifying for the number of amyloid-beta plaques instead of stained surface area, atypical AD cases differed in distribution pattern from typical AD cases. Remarkably, plaque morphology and localization of neuroinflammation within the plaques was different between the two phenotypes.

Conclusions: Our data show a different localization of neuroinflammatory markers and amyloid-beta plaques between $A D$ phenotypes. In addition, these markers reflect the atypical distribution of tau pathology in atypical AD, suggesting that neuroinflammation might be a crucial link between amyloid-beta deposits, tau pathology, and clinical symptoms.
\end{abstract}

Keywords: Atypical Alzheimer's disease, Microglia, Complement, Human brain tissue, Neuroinflammation, Amyloid-beta plaque

\footnotetext{
* Correspondence: b.boon@vumc.nl

${ }^{1}$ Department of Neurology, Alzheimer Center, Amsterdam Neuroscience, VU

University Medical Center, Amsterdam, The Netherlands

2Department of Pathology, Amsterdam Neuroscience, VU University Medical

Center, Amsterdam, The Netherlands
}

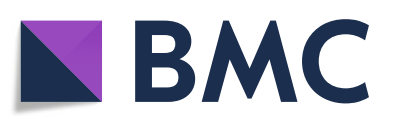

(c) The Author(s). 2018 Open Access This article is distributed under the terms of the Creative Commons Attribution 4.0 International License (http://creativecommons.org/licenses/by/4.0/), which permits unrestricted use, distribution, and reproduction in any medium, provided you give appropriate credit to the original author(s) and the source, provide a link to the Creative Commons license, and indicate if changes were made. The Creative Commons Public Domain Dedication waiver (http://creativecommons.org/publicdomain/zero/1.0/) applies to the data made available in this article, unless otherwise stated. 


\section{Background}

Patients with Alzheimer's disease (AD) typically present with episodic memory impairment followed by deterioration of executive functioning, praxis, and visuospatial skills. However, AD patients may also present with an atypical phenotype [1, 2]. An atypical presentation is seen in $10 \%$ of the late-onset $\mathrm{AD}$ (LOAD) patients ( $\geq 65$ years of age) and up to $30 \%$ of the early onset ( $<65$ years) AD (EOAD) patients [3]. So far, three variants of atypical $\mathrm{AD}$ have been described: the posterior cortical atrophy (PCA) variant characterized by visuoperceptual problems [4], the logopenic variant characterized by aphasia [5], and the frontal variant associated with behavioral changes $[1,2]$. In addition to clinical differences, these different AD variants show syndrome-specific atrophy patterns on MRI [6].

$\mathrm{AD}$ is characterized by the deposition of amyloid-beta plaques and the formation of neurofibrillary tangles (NFT) in the brain. During disease progression, both plaques and NFTs are assumed to spread through the brain in a fixed order [7, 8]. However, the typical NFT distribution as originally described by Braak and Braak [9] does not seem to hold for all AD cases. Clinicopathological studies indicated that AD patients with an atypical phenotype have an atypical NFT distribution $[9,10]$. Furthermore, this atypical NFT distribution was demonstrated in living $\mathrm{AD}$ patients using the tau tracer $\left[{ }^{18} \mathrm{~F}\right] \mathrm{AV} 1451$ [11]. While the atypical distribution of NFTs corresponds with the observed clinical phenotype, the cause of this difference in NFT spreading between AD variants remains elusive.

There is accumulating evidence that inflammation plays a prominent role in the pathogenesis of AD. Recently, genome-wide association studies have identified several genes involved in inflammation, especially those engaged in microglia function, as risk factors for developing $\mathrm{AD}$ [12-15]. The AD brain shows an increased presence of activated microglia, reactive astrocytes, proinflammatory cytokines, acute phase proteins, and activated complement proteins compared to controls [16]. Complement proteins co-localize with NFTs $[17,18]$, as well as with amyloid-beta deposits [19], and are actively involved in the formation of these pathological structures. Clusters of activated microglia are found in amyloid plaques, and the presence of activated microglia increases with disease severity $[20,21]$. Recent disease models suggest that microglia are actively involved in the spreading of phosphorylated Tau (pTau) [22-24]. Tau pathology is heavily reduced in disease-modeled mice that are depleted for microglia compared to their microglia-positive peers [23, 24]. In the human brain, the presence of activated microglia correlates with Braak staging for NFTs [25].
Evidence for the correlation of pTau, neuroinflammation, and microglia in $\mathrm{AD}$ subtypes is lacking. In this study, we aimed to explore whether an atypical spreading of NFT pathology in non-amnestic AD is associated with an atypical distribution of neuroinflammation. In a well-defined cohort of typical and atypical AD, we assessed and compared the presence of pTau, amyloidbeta, (activated) glial cells, and complement proteins in temporal and parietal cortical areas.

\section{Methods}

\section{Post-mortem brain tissue}

Post-mortem brain tissue was obtained from the Netherlands Brain Bank (NBB; Amsterdam, The Netherlands). Donors signed informed consent for brain autopsy, and the use of brain tissue and medical records for research purposes. Neuropathological diagnosis was based on histochemical stainings including hematoxylin and eosin, congo red staining, Bodian or Gallyas and methenamine silver stainings, and immunohistochemical stainings for amyloid-beta, pTau, alpha-synuclein, and p62. These stainings were performed on formalin-fixed paraffin-embedded (FFPE) brain tissue of multiple brain regions including the frontal cortex, temporal pole, superior parietal lobe, occipital pole, amygdala, and the hippocampus. Neuropathological diagnosis of AD was based on Braak stages for NFT and amyloid [7], Thal phases for amyloid-beta [8], and CERAD criteria for neuritic plaques [26].

\section{Selection of typical and atypical AD cases}

Between 1996 and 2014, 352 AD cases came to autopsy and were semi-quantitatively scored by two neuropathologists (WK, AR) for the NFT load using Bodian or Gallyas staining in the temporal pole, the frontal, superior parietal, and occipital cortex as previously described by Hoogendijk et al. [27]. The NFT load was scored in a $0.4-\mathrm{mm}^{2}$ area as being absent (0), sparse (1), mild (2; 2 to 3 NFTs), or severe $(3 ;>3$ NFTs) for each brain region separately. From this cohort, we selected cases with an NFT score of 3 in either the temporal or parietal section, or in both sections, resulting in 296 cases (for flowchart, see Fig. 1). For 142 cases, the NFT score was higher in the temporal section than the parietal section. These cases were referred to as having a typical NFT distribution [7]. In 126 of 296 cases, an NFT score of 3 was found in the temporal as well as the parietal section. A higher NFT score in the parietal compared to the temporal section was observed in 28 cases and was defined as a parietal dominant and thus atypical NFT distribution.

To study the distribution of neuroinflammation in typical and atypical AD, we further refined our cohort to include only cases with a concordance between clinical presentation and NFT distribution. The clinical 


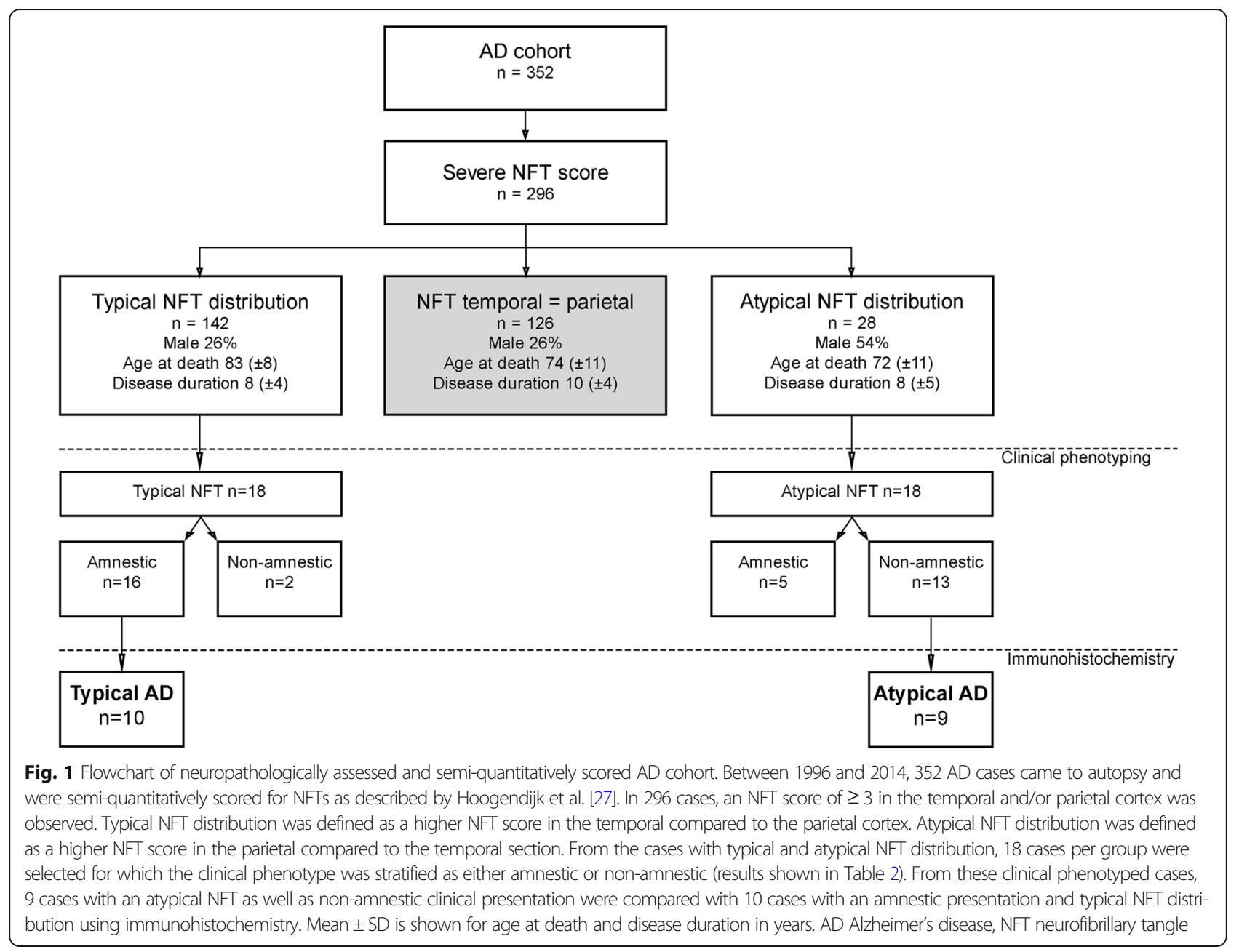

phenotype of 36 cases with atypical and typical NFT pathology was retrospectively assessed. In 18 out of 28 cases with an atypical NFT distribution, the available clinical information was sufficient to come to a retrospective clinical diagnosis (see Table 1 for demographics). To have an equal group for comparison, we randomly chose 18 cases with both typical NFT distribution and sufficient clinical information for clinical phenotyping. Clinical assessment was performed retrospectively and independently by 2 cognitive neurologists (YP and FB) using the NIA-AA criteria [2]. Both clinicians were blinded to the pathological stratification

Table 1 Demographics of 36 cases with typical and atypical NFT distribution for which extensive retrospective clinical assessment was performed

\begin{tabular}{|c|c|c|c|c|}
\hline & $\begin{array}{l}\text { Typical NFT distribution } \\
n=18\end{array}$ & & $\begin{array}{l}\text { Atypical NFT distribution } \\
n=18\end{array}$ & \\
\hline Phenotype & Amnestic $(n=16)$ & Non-amnestic $(n=2)$ & Amnestic $(n=5)$ & Non-amnestic $(n=13)$ \\
\hline Male, $n(\%)$ & $6(37)$ & 0 & $3(60)$ & $8(62)$ \\
\hline Age at death & $82( \pm 7)$ & $88( \pm 5)$ & $71( \pm 11)$ & $67( \pm 7)$ \\
\hline Disease duration & $8( \pm 5)$ & $7( \pm 4)$ & $11( \pm 5)$ & $8( \pm 4)$ \\
\hline \multicolumn{5}{|l|}{ NFT stage [7] } \\
\hline$n$ per stage $4 / 5 / 6$ & $2 / 10 / 4$ & $1 / 1 / 0$ & $0 / 2 / 3$ & $0 / 7 / 6$ \\
\hline \multicolumn{5}{|l|}{ Amyloid stage [7] } \\
\hline$n$ per stage $\mathrm{O} / \mathrm{A} / \mathrm{B} / \mathrm{C}$ & $0 / 0 / 16$ & $0 / 0 / 2$ & $0 / 0 / 5$ & $0 / 1 / 12$ \\
\hline
\end{tabular}

Data are mean \pm SD. Age at death and disease duration shown in years NFT neurofibrillary tangle 
when assessing the clinical phenotype. The clinical stratification was based on (collateral) history and cognitive examination documented by the clinical neurologist. Cases with first-degree relatives affected by EOAD were excluded to minimize the risk of genetic AD. Other exclusion criteria were sepsis, other neurodegenerative or psychiatric diseases, significant cerebrovascular disease, post-mortem interval $>12 \mathrm{~h}$, and prior known genetic mutations. Due to our exclusion criteria and availability of archived brain tissue samples, our inclusion was limited to 9 atypical AD cases and 10 typical AD cases of which the temporal pole and superior parietal lobe were assessed by immunohistochemistry (see Fig. 1 for inclusion flowchart, Table 2 for patient details, and Table 4 for demographics in the "Results" section). Cases were not intentionally matched for disease duration, brain weight, ApoE status, or post-mortem interval.

\section{Immunohistochemistry (IHC)}

IHC was performed to detect pTau (AT8); amyloid-beta (N-terminal; IC16); reactive astrocytes (GFAP); microglia (Iba1); activated microglia (CD68 and HLA-DP/DQ/DR); and complement proteins $\mathrm{C} 1 \mathrm{q}, \mathrm{C} 3 \mathrm{~d}, \mathrm{C} 4 \mathrm{~b}$, and C5b-9 (Table 3). FFPE sections (5- $\mu$ m thick) from the temporal pole and superior parietal lobe of the right hemisphere were used.

IHC for pTau, amyloid-beta, GFAP, and Iba1 was performed using the Ventana BenchMark ULTRA staining system (Roche, Basel, Switzerland). Tissue sections were mounted on TOMO adhesive glass slides (Matsunami, Osaka, Japan) and deparaffinized. After blocking for endogenous peroxidase, antigen retrieval was performed by heating sections at $100{ }^{\circ} \mathrm{C}$ in Cell Conditioning 1 solution ( $\mathrm{pH}$ 8.5) (Roche) for different durations per antibody (see Table 3). For detection of primary

Table 2 Clinical and neuropathological characteristics of typical and atypical AD cases

\begin{tabular}{|c|c|c|c|c|c|c|c|c|c|c|c|}
\hline Case & Phenotype & Symptoms at clinical presentation & Sex & $\begin{array}{l}\text { Age at } \\
\text { death }\end{array}$ & $\begin{array}{l}\text { Disease } \\
\text { duration }\end{array}$ & $\begin{array}{l}\text { NFT } \\
\text { stage [7] }\end{array}$ & $\begin{array}{l}\text { Amyloid } \\
\text { stage [7] }\end{array}$ & $\begin{array}{l}\text { Brain } \\
\text { weight (grams) }\end{array}$ & Cause of death & PMI & $\overline{A p o E}$ \\
\hline 1 & Typical AD & Memory & $\mathrm{F}$ & 92 & 8 & 5 & C & 933 & Heart failure & $7: 00$ & 43 \\
\hline 2 & Typical AD & Memory, disorientation & $\mathrm{F}$ & 84 & 4 & 4 & C & 908 & $\begin{array}{l}\text { Cardiogenic } \\
\text { shock }\end{array}$ & $4: 15$ & 32 \\
\hline 3 & Typical AD & Memory, disorientation & $\mathrm{F}$ & 84 & 9 & 5 & C & 827 & Cachexia & $6: 40$ & 43 \\
\hline 4 & Typical AD & Memory & $\mathrm{F}$ & 89 & 5 & 5 & C & 962 & Pneumonia & $6: 28$ & 43 \\
\hline 5 & Typical AD & Memory & $\mathrm{F}$ & 83 & 6 & 6 & C & 1100 & Dehydration & $6: 17$ & 43 \\
\hline 6 & Typical AD & Memory, behavior & $\mathrm{F}$ & 91 & 3 & 4 & C & 1026 & Cachexia & $6: 25$ & 33 \\
\hline 7 & Typical AD & Memory, & $\mathrm{F}$ & 77 & 2 & 5 & C & 999 & Pneumonia & $6: 05$ & 33 \\
\hline 8 & Typical AD & Memory, behavior & M & 70 & 2 & 6 & C & 1261 & $\begin{array}{l}\text { Metastasized } \\
\text { colon carcinoma }\end{array}$ & $6: 20$ & 43 \\
\hline 9 & Typical AD & Memory & $\mathrm{F}$ & 76 & 12 & 5 & C & 1223 & Unknown & $10: 45$ & 44 \\
\hline 10 & Typical AD & Memory & M & 60 & 2 & 6 & C & 1191 & Cachexia & $6: 15$ & 43 \\
\hline 11 & Atypical AD & $\begin{array}{l}\text { Aphasia, dyscalculia, agraphia, } \\
\text { left-right agnosia, } \\
\text { visuoconstruction problems }\end{array}$ & $\mathrm{F}$ & 65 & 6 & 6 & C & 975 & Pneumonia & $5: 40$ & 33 \\
\hline 12 & Atypical AD & $\begin{array}{l}\text { Aphasia, dyslexia, apraxia, } \\
\text { visuoconstruction problems }\end{array}$ & M & 65 & 2 & 6 & C & 1057 & $\begin{array}{l}\text { Cardiac } \\
\text { insufficiency }\end{array}$ & $8: 50$ & 44 \\
\hline 13 & Atypical AD & $\begin{array}{l}\text { Aphasia, acalculia, } \\
\text { fingeragnosia, apraxia }\end{array}$ & M & 64 & 7 & 5 & C & 1135 & Pneumonia & $4: 45$ & 42 \\
\hline 14 & Atypical AD & $\begin{array}{l}\text { Parkinsonism, falling, alien } \\
\text { hand syndrome }\end{array}$ & $\mathrm{F}$ & 67 & 3 & 5 & C & 817 & Epileptic insult & $7: 35$ & 33 \\
\hline 15 & Atypical AD & Aphasia, apathy, agitation & M & 59 & 6 & 6 & C & 1300 & Cachexia & 5:05 & 44 \\
\hline 16 & Atypical AD & $\begin{array}{l}\text { Aphasia, dyscalculia, dyslexia, } \\
\text { disorientation }\end{array}$ & M & 62 & 3 & 6 & C & 1116 & $\begin{array}{l}\text { Malign } \\
\text { neuroleptic } \\
\text { syndrome }\end{array}$ & $4: 15$ & 43 \\
\hline 17 & Atypical AD & Aphasia, dyslexia, apathy, apraxia & M & 65 & 1 & 5 & C & 1150 & Euthanasia & $6: 50$ & 43 \\
\hline 18 & Atypical AD & $\begin{array}{l}\text { Aphasia, dyslexia, apraxia, } \\
\text { visuospatial problems, behavior }\end{array}$ & M & 62 & 6 & 5 & $\mathrm{~B}$ & 1153 & Cachexia & $4: 40$ & 33 \\
\hline 19 & Atypical AD & Visual hallucinations, psychosis & M & 61 & 6 & 6 & C & 1355 & Pneumonia & $5: 00$ & 43 \\
\hline
\end{tabular}

Age at death and disease duration in years; post-mortem interval in hours to minutes. Typical AD defined as more neurofibrillary tangles in the temporal compared to the parietal cortex by semi-quantitative scoring as described by Hoogendijk et al. [27] and an amnestic presentation during life. Atypical AD defined as more neurofibrillary tangles assessed by semi-quantitative scoring in the parietal compared to the temporal cortex and a non-amnestic presentation

$A D$ Alzheimer's disease, $F$ female, $M$ male, NFT neurofibrillary tangle, $P M I$ post-mortem interval 
Table $\mathbf{3}$ Characteristics of primary antibodies and staining details

\begin{tabular}{|c|c|c|c|c|c|c|c|}
\hline Antibody & Antigen & Species & Origin details & Dilution & $\begin{array}{l}\text { Incubation } \\
\text { time }\end{array}$ & Antigen retrieval & $\begin{array}{l}\text { Detection } \\
\text { method }\end{array}$ \\
\hline pTau, clone AT8 & $\begin{array}{l}\text { Tau phosphorylated at Ser202 } \\
\text { and Thr205 }\end{array}$ & $\begin{array}{l}\text { Mouse } \\
\operatorname{lgG1}\end{array}$ & ThermoFisher, Pittsburgh, USA & 1:10000 & $\begin{array}{l}32 \mathrm{~min} \\
\text { at } 36^{\circ} \mathrm{C}\end{array}$ & $\begin{array}{l}\text { Heat-induced (pH 8.5) } \\
\text { for } 24 \text { min }\end{array}$ & Optiview \\
\hline $\begin{array}{l}\text { Amyloid-beta, } \\
\text { clone IC-16 }\end{array}$ & $\begin{array}{l}\text { N-terminus of amyloid-beta } \\
\text { (aa 1-16) }\end{array}$ & $\begin{array}{l}\text { Mouse } \\
\operatorname{lgG} 2 a\end{array}$ & $\begin{array}{l}\text { Dr. Carsten Korth, University } \\
\text { of Dusseldorf, Germany }\end{array}$ & $1: 25$ & $\begin{array}{l}32 \min \\
\text { at } 36^{\circ} \mathrm{C}\end{array}$ & $\begin{array}{l}\text { Heat-induced (pH 8.5) } \\
\text { for } 24 \text { min }\end{array}$ & Optiview \\
\hline $\begin{array}{l}\text { GFAP, clone } \\
\text { EP672Y }\end{array}$ & Glial fibrillary acidic protein & Mouse & Roche, Basel, Switzerland & $1: 2$ & $\begin{array}{l}8 \min \\
\text { at } 37^{\circ} \mathrm{C}\end{array}$ & $\begin{array}{l}\text { Heat-induced (pH 8.5) } \\
\text { for } 32 \text { min }\end{array}$ & Optiview \\
\hline lba1 & C-terminus of Iba1 & Rabbit & $\begin{array}{l}\text { Wako Pure Chemical } \\
\text { Industries, Osaka, Japan }\end{array}$ & $1: 4000$ & $\begin{array}{l}32 \min \\
\text { at } 36^{\circ} \mathrm{C}\end{array}$ & $\begin{array}{l}\text { Heat-induced (pH 8.5) } \\
\text { for } 16 \text { min }\end{array}$ & Optiview \\
\hline $\begin{array}{l}\text { CD68, clone } \\
\text { KP1 }\end{array}$ & CD68 & $\begin{array}{l}\text { Mouse } \\
\operatorname{lgG1}\end{array}$ & Dako, Glostrup, Denmark & $1: 1200$ & $\begin{array}{l}\text { Overnight } \\
\text { at } 4^{\circ} \mathrm{C}\end{array}$ & $\begin{array}{l}\text { Heat-induced ( } \mathrm{pH} 6.0) \\
\text { by autoclave }\end{array}$ & EnVision \\
\hline $\begin{array}{l}\text { HLA-DP/DQ/DR, } \\
\text { clone CR3/43 }\end{array}$ & $\begin{array}{l}\text { Alpha and beta-chains of all } \\
\text { products of the } D P, D Q \text {, and } \\
\text { DR subregions }\end{array}$ & $\begin{array}{l}\text { Mouse } \\
\operatorname{lgG1}\end{array}$ & Dako & $1: 800$ & $\begin{array}{l}\text { Overnight } \\
\text { at } 4^{\circ} \mathrm{C}\end{array}$ & $\begin{array}{l}\text { Heat-induced ( } \mathrm{pH} 6.0) \\
\text { by autoclave }\end{array}$ & EnVision \\
\hline $\mathrm{Clq}$ & $\mathrm{Clq}$ & Rabbit & Dako & $1: 25600$ & $\begin{array}{l}\text { Overnight } \\
\text { at } 4^{\circ} \mathrm{C}\end{array}$ & $\begin{array}{l}\text { Heat-induced ( } \mathrm{pH} 6.0) \\
\text { by autoclave }\end{array}$ & EnVision \\
\hline C3d & C3d & Rabbit & Dako & $1: 3200$ & $\begin{array}{l}\text { Overnight } \\
\text { at } 4^{\circ} \mathrm{C}\end{array}$ & $\begin{array}{l}\text { Heat-induced (pH 6.0) } \\
\text { by autoclave }\end{array}$ & EnVision \\
\hline$c 4 b$ & $c 4 b$ & Rabbit & $\begin{array}{l}\text { Abcam, Cambridge, United } \\
\text { Kingdom }\end{array}$ & $1: 1600$ & $\begin{array}{l}\text { Overnight } \\
\text { at } 4^{\circ} \mathrm{C}\end{array}$ & $\begin{array}{l}\text { Heat-induced (pH 6.0) } \\
\text { by autoclave }\end{array}$ & EnVision \\
\hline $\begin{array}{l}\text { C5b-9, clone } \\
\text { WU13-15 }\end{array}$ & $\begin{array}{l}\text { Neoepitope on C9 in the } \\
\text { membrane attack complex }\end{array}$ & Mouse & $\begin{array}{l}\text { Hycult Biotech, Plymouth } \\
\text { meeting, USA }\end{array}$ & $1: 400$ & $\begin{array}{l}\text { Overnight } \\
\text { at } 4^{\circ} \mathrm{C}\end{array}$ & $\begin{array}{l}\text { Heat-induced (pH 6.0) } \\
\text { by autoclave }\end{array}$ & EnVision \\
\hline
\end{tabular}

antibodies with 3,3'-diaminobenzidine tetrahydrochloride (DAB), Optiview DAB IHC detection kit (Roche) was used. Finally, the sections were mounted with Coverslipping film (Sakura Tissue-Tek, Leiden, The Netherlands).

IHC for CD68, HLA-DP/DQ/DR, C1q, C3d, C4b, and C5b-9 was performed manually. The sections were mounted on SuperFrost Plus glass slides (Menzel-Gläser, Braunschweig, Germany) and deparaffinized. Subsequently, the sections were blocked for endogenous peroxidase using $0.3 \%$ hydrogen peroxide in phosphate buffer saline (PBS; pH 7.4). The sections were immersed in sodium citrate buffer $(10 \mathrm{mM}$ sodium citrate, $5 \mathrm{M}$ $\mathrm{NaOH}, \mathrm{dH}_{2} \mathrm{O}, \mathrm{pH}$ 6.0) and heated to $120{ }^{\circ} \mathrm{C}$ in an autoclave for antigen retrieval. Primary antibodies were diluted in normal antibody diluent (ImmunoLogic, Duiven, The Netherlands) and incubated overnight at $4{ }^{\circ} \mathrm{C}$. Primary antibodies were detected using EnVision (Dako, Glostrup, Denmark). Between steps, the sections were washed in PBS. Subsequently, antibodies were visualized with DAB (Dako). After counterstaining with hematoxylin, the sections were mounted with Entellan (Merck, Darmstadt, Germany).

\section{Image analyses and quantitative assessment of immunostainings}

For quantitative assessment, 2 regions of interest (ROI) were randomly selected within non-curved areas of each section containing all 6 cortical layers [28]. Within each ROI, contiguous microscopic fields arranged in columns perpendicular to the cortical surface of the cortex were photographed. Total surface, depending on the width of the cortex, could vary for each ROI and contained at least 2 columns. Images were taken using a $\times 10$ objective on an Olympus BX 41 photomicroscope with a Leica MC 170 HD digital camera. The presence of DAB staining was quantified with Image $(\mathrm{NIH})$ using the color threshold plugin. Our outcome measurement was the percentage of DAB-stained area per marker, also referred to as immunoreactivity. In addition to immunoreactivity, we quantified the number of amyloid-beta and C4b plaques. For the amyloid-beta plaques, diffuse deposits were not taken into account and only dense plaques were quantified, defined as particles with an immunoreactive surface area of $100 \mu^{2}$ or more [29, 30]. C4b-positive deposits of the same surface area were quantified as a measurement of the atypical appearing plaques as described in the "Results" section.

\section{Fluorescent triple stainings}

Co-localization of C4b and CD68 or HLA-DP/DQ/DR with amyloid-beta and thioflavine $S$ was visualized in the parietal section of 4 atypical AD cases and the temporal section of 2 typical AD cases. The typical AD cases served as positive controls and reference since localization of complement and microglia in classicalcored plaques is widely described in literature (for CD68 [20]/for complement $[16,19])$.

After deparaffinization, the sections were submerged in sodium citrate buffer and heated to $120{ }^{\circ} \mathrm{C}$ in an 
autoclave. Subsequently, the sections were incubated using different combinations of primary antibodies: mouse IgG2a-anti-amyloid-beta (1:200), rabbit-anti-C4b (1:200), and mouse IgG1-anti-HLA-DP/DQ/DR (1:25) or mouse IgG1-anti-CD68 (1:300). Antibodies were diluted in normal antibody diluent (ImmunoLogic) and incubated overnight at $4{ }^{\circ} \mathrm{C}$. Subsequently, the sections were incubated with the following secondary antibodies: goatanti-mouse IgG2a Alexa Fluor dye 594, goat-anti-mouse IgG1 Alexa Fluor dye 647, and donkey-anti-rabbit Alexa Fluor dye 647 (1:250 dilution, ThermoFisher, Waltham, USA). For visualization of amyloid structures, the sections were counterstained with thioflavine $\mathrm{S}(1 \%$ in $\mathrm{dH}_{2} \mathrm{O}$ ) and subsequently rinsed in 70\% ethanol. Autofluorescence was blocked with $0.1 \%$ Sudan black in $70 \%$ ethanol for $5 \mathrm{~min}$. Between steps, the sections were rinsed with PBS. Finally, the sections were enclosed with $80 \%$ glycerol $/ 20 \%$ tris buffered saline. Representative pictures were taken with a Leica DMi8 inverted fluorescent microscope equipped with a Leica DFC300 G camera.

\section{Statistical analysis}

Demographics of the typical and atypical AD groups were compared using Fisher's exact test for categorical and Mann-Whitney $U$ test for numerical and not normally distributed data. Outcome measures were compared between the $2 \mathrm{AD}$ groups by using linear mixed model analysis. Linear mixed model analysis was used to adjust for the nested observations within cases. In the linear mixed model analyses, the group variable (typical versus atypical AD), the region (temporal versus parietal), and the interaction between group and region were added. Correcting for age and sex made the model less stable and was therefore not performed. An assumption to apply a linear mixed model is that residuals of outcome measurements are normally distributed. To meet this assumption, all outcome variables (pTau, amyloid-beta, GFAP, Iba1, HLA-DP/DQ/DR, CD68, C1q, C3d, C4b, number of amyloid-beta plaques, and number of $C 4 b$ plaques) were transformed by taking the natural $\log$ of the (variable +1$)$. The covariance structure was set to unstructured. Using the linear mixed model, we answered if the difference in outcome measurement over the 2 regions was different between the $2 \mathrm{AD}$ phenotypes (region $\times$ phenotype), also referred to as interaction effect. Both phenotypes showed a similar distribution over the 2 regions if no interaction effect was found. Statistical analysis was performed in IBM SPSS statistics version 22.0 (IBM SPSS Statistics, Armonk, NY, USA). Bonferroni correction was used to correct for multiple testing. Since we tested 11 outcome measurements (amyloid-beta, pTau, GFAP, Iba1, CD68, HLA-DP/DQ/DR, C1q, C3d, C4b, \# amyloid-beta plaques, and \# C4b plaques), statistical significance was set at $p<.0045$ ( $p<.05 / 11$ outcome measurements) for each effect (region $\times$ phenotype and region) of the linear mixed model. Statistical significance was set at $p<.05$ for comparison of baseline characteristics.

\section{Results \\ Atypical AD cases are younger than typical AD cases}

The post-mortem cohort used for IHC consisted of 9 atypical AD cases and 10 typical AD cases. For a summary of initial clinical symptoms at presentation for each case, see Table 2. Most atypical AD cases presented with symptoms of aphasia, consisting of word-finding difficulties and spelling mistakes, combined with apraxia. None of our atypical cases retrospectively met the criteria for an isolated primary progressive aphasia [5]. One case presented with Parkinsonism and an alien hand syndrome, fitting a corticobasal syndrome during life. All 10 typical AD cases presented with memory complaints as most prominent initial symptom. Demographic characteristics of both $\mathrm{AD}$ phenotypes used for immunohistochemical analysis are shown in Table 4. Similar to the large cohort of 296 AD subjects (see Fig. 1), atypical AD patients selected for IHC analysis were younger at age of death and more often male. The disease duration, brain weight, post-mortem interval, disease severity, and ApoE genotype did not differ between groups.

\section{Distribution of pTau and amyloid-beta in typical and atypical AD}

Immunohistochemistry for pTau showed neuronal inclusions as well as neuritic threads (Fig. 2a). Typical AD cases showed more pTau immunoreactivity in the temporal compared to the parietal section (Fig. 2c). This was contrary to the pTau distribution in atypical AD cases, in which the parietal section showed more

Table 4 Demographic characteristics of the AD cases used for immunohistochemical analysis

\begin{tabular}{llll}
\hline & $\begin{array}{l}\text { Typical AD } \\
(n=10)\end{array}$ & $\begin{array}{l}\text { Atypical AD } \\
(n=9)\end{array}$ & $p$-value \\
\hline Male, $n$ & 2 & 7 & $<.05$ \\
Age at death & $81( \pm 10)$ & $63( \pm 3)$ & $<.01$ \\
Disease duration & $5( \pm 3)$ & $4( \pm 2)$ & .78 \\
Brain weight (grams) & $1043( \pm 146)$ & $1117( \pm 161)$ & .32 \\
PMl (h:min) & $6: 19( \pm 1: 48)$ & $5: 51( \pm 1: 33)$ & .66 \\
$\begin{array}{l}\text { NFT stage [7] } \\
n \text { per stage 4/5/6 }\end{array}$ & $2 / 5 / 3$ & $0 / 4 / 5$ & .46 \\
$\begin{array}{l}\text { Amyloid stage [7] } \\
n \text { per stage O/A/B/C }\end{array}$ & $0 / 0 / 10$ & $0 / 1 / 8$ & .47 \\
$\begin{array}{l}\text { ApoE genotype } \\
n \text { per category }\end{array}$ & $1 / 2 / 0 / 6 / 1$ & $0 / 3 / 1 / 3 / 2$ & .48 \\
\begin{tabular}{l} 
32/33/42/43/44 \\
\hline Data in mean ( $\mathrm{SD}) . \mathrm{Age}$
\end{tabular} & & & \\
\hline
\end{tabular}

Data in mean $( \pm S D)$. Age at death and disease duration in years. Mann-Whitney $U$ test for continuous data. Fisher's exact test for categorical data

$A D$ Alzheimer's disease, NFT neurofibrillary tangle, $P M I$ post-mortem interval 


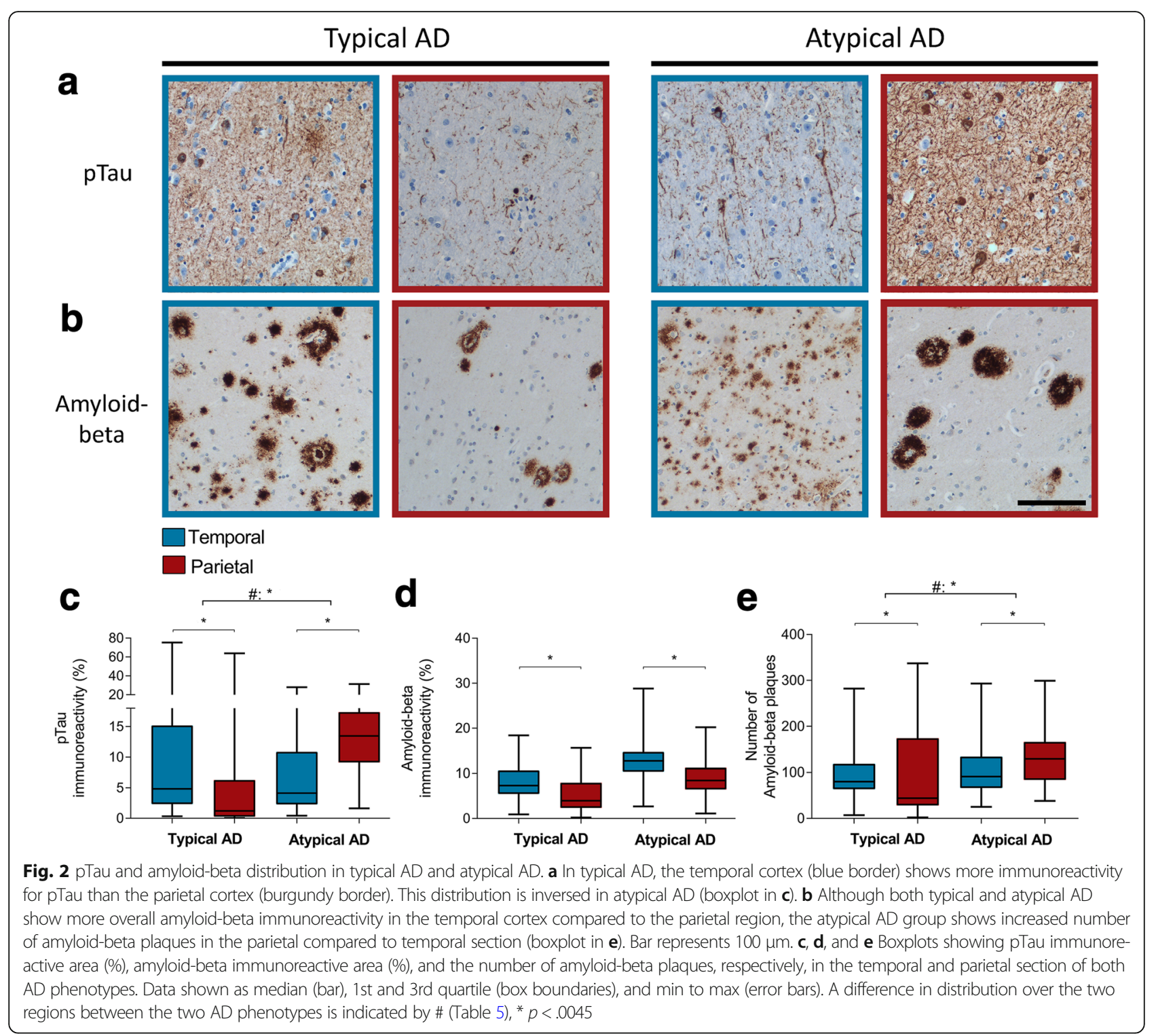

immunoreactivity compared to the temporal section. In addition, the distribution of pTau over the 2 regions differed significantly between the 2 phenotypes (Table 5).

Amyloid-beta immunoreactivity was present in the form of diffuse deposits, dense plaques, and classical cored plaques (Fig. 2b). Both the typical and atypical AD group showed more immunoreactivity for amyloid-beta in the temporal than parietal section (Fig. 2d), and no difference in distribution was observed (Table 5). While total immunoreactivity levels did not show differences between the 2 phenotypes, the number of dense plaques with an immunoreactive surface area of $100 \mu \mathrm{m}^{2}$ or more did show a significant difference in distribution over the 2 regions between the 2 phenotypes (Fig. 2e) (Table 5). In contrast to the typical AD group, more dense plaques were observed in the parietal section of the atypical $\mathrm{AD}$ group. Besides a difference in plaque number, we observed a contrast in plaque morphology between the two groups, which will be addressed below.

\section{Glial activation is increased in atypical AD}

Staining for GFAP-positive astrocytes showed variably sized star-like GFAP-positive structures in all AD cases (Fig. 3a). Both phenotypes showed higher levels of immunoreactivity for GFAP in the temporal section compared to the parietal section. Atypical AD cases showed relatively more GFAP immunoreactivity in the parietal cortex compared to typical AD cases (Fig. 3c; Table 5).

Iba1 immunostaining showed positivity in both the cell soma as well as the processes of the microglia, mostly in the form of ramified microglia (Fig. 3b). 
Table 5 Results for the linear mixed model of transformed immunohistochemistry variables

\begin{tabular}{|c|c|c|c|c|}
\hline \multirow[t]{2}{*}{ Transformed variable } & \multirow[t]{2}{*}{ Fixed Effect } & \multirow[t]{2}{*}{ Phenotype } & \multicolumn{2}{|c|}{ Results for linear mixed model } \\
\hline & & & Beta-coefficient & $95 \% \mathrm{Cl}$ \\
\hline \multirow[t]{3}{*}{ pTau } & Region x phenotype & & $1.53^{*}$ & {$[1.33-1.72]$} \\
\hline & Region & Typical AD & $-0.82^{*}$ & {$[-0.95--0.68]$} \\
\hline & & Atypical AD & $0.71^{*}$ & {$[0.57-0.85]$} \\
\hline \multirow[t]{2}{*}{ Amyloid-beta } & Region $x$ phenotype & & 0.04 & {$[-0.06-0.15]$} \\
\hline & Region & Both & $-0.46^{*}$ & {$[-0.54--0.39]$} \\
\hline \multirow[t]{3}{*}{ GFAP } & Region x phenotype & & $1.25^{*}$ & {$[1.02-1.48]$} \\
\hline & Region & Typical AD & $-1.71^{*}$ & {$[-1.87--1.56]$} \\
\hline & & Atypical AD & $-0.46^{*}$ & {$[-0.63--0.29]$} \\
\hline \multirow[t]{2}{*}{ |ba1 } & Region x phenotype & & 0.10 & {$[0.002-0.19]$} \\
\hline & Region & Both & $-0.47^{*}$ & {$[-0.53--0.41]$} \\
\hline \multirow[t]{3}{*}{ CD68 } & Region $\mathrm{x}$ phenotype & & $-0.43^{*}$ & {$[0.38-0.48]$} \\
\hline & Region & Typical AD & $-0.13^{*}$ & {$[-0.17--0.10]$} \\
\hline & & Atypical AD & $0.29^{*}$ & {$[0.26-0.33]$} \\
\hline \multirow[t]{3}{*}{ HLA-DP/DQ/DR } & Region $x$ phenotype & & $0.97^{*}$ & {$[0.88-1.06]$} \\
\hline & Region & Typical AD & $-0.08^{*}$ & {$[-0.14--0.03]$} \\
\hline & & Atypical AD & $0.89^{*}$ & {$[0.82-0.96]$} \\
\hline \multirow[t]{2}{*}{$\mathrm{Clq}$} & Region x phenotype & & -0.05 & {$[-0.15-0.06]$} \\
\hline & Region & Both & 0.03 & {$[-0.05-0.10]$} \\
\hline \multirow[t]{3}{*}{ C3d } & Region x phenotype & & $0.74^{*}$ & {$[0.62-0.86]$} \\
\hline & Region & Typical AD & $-0.39^{*}$ & {$[-0.47--0.31]$} \\
\hline & & Atypical AD & $0.36^{*}$ & {$[0.26-0.45]$} \\
\hline \multirow[t]{3}{*}{$c 4 b$} & Region x phenotype & & $0.95^{*}$ & {$[0.84-1.07]$} \\
\hline & Region & Typical AD & $-0.24^{*}$ & {$[-0.32--0.17]$} \\
\hline & & Atypical AD & $0.71^{*}$ & {$[0.62-0.80]$} \\
\hline \multirow[t]{3}{*}{ \# of amyloid-beta plaques } & Region x phenotype & & $0.58^{*}$ & {$[0.41-0.75]$} \\
\hline & Region & Typical AD & $-0.33^{*}$ & {$[-0.44--0.21]$} \\
\hline & & Atypical AD & $0.25^{*}$ & {$[0.13-0.37]$} \\
\hline \multirow[t]{3}{*}{ \# of C4b plaques } & Region x phenotype & & $1.84^{*}$ & {$[1.58-2.11]$} \\
\hline & Region & Typical AD & $-0.39^{*}$ & {$[-0.56--0.22]$} \\
\hline & & Atypical AD & $1.46^{*}$ & {$[1.25-1.66]$} \\
\hline
\end{tabular}

Results of the linear mixed model for analyzed immunohistochemistry variables are shown. All variables were transformed: In(variable +1$)$. We tested if the distribution over the 2 regions was different between the 2 AD phenotypes, defined as the interaction effect: region $\times$ phenotype. When an interaction effect was found, the beta-coefficient is shown per phenotype. To correct for multiple testing, a $p$ value $<.0045$ was considered significant $(p<.05 / 11$ outcome measurements) and indicated with *

$A D$ Alzheimer's disease, $\mathrm{Cl}$ confidence interval

\# Number

Both AD groups showed a similar temporal dominancy for Iba1.

Activated microglia were stained using CD68 and HLA-DP/DQ/DR. Whereas CD68 positivity was mostly found in the soma of microglia, HLA-DP/DQ/DR showed a prominent staining in the processes of microglia (Fig. 4a, b).

Both markers showed a different distribution over the 2 regions between the $2 \mathrm{AD}$ phenotypes (Fig. 4c, d; Table 5). Atypical AD cases showed more immunoreactivity for
CD68 and HLA-DP/DQ/DR in the parietal compared to the temporal section, which was in contrast to the typical AD cases. In addition, the levels of CD68 and HLA$\mathrm{DP} / \mathrm{DQ} / \mathrm{DR}$ immunoreactivity were relatively high in the parietal section of atypical AD compared to the temporal section of typical AD.

Increased presence of complement proteins in atypical AD To visualize different parts of the complement cascade, we stained for $\mathrm{C} 1 \mathrm{q}, \mathrm{C} 3 \mathrm{~d}$, and $\mathrm{C} 4 \mathrm{~b}$, representing the start of the 


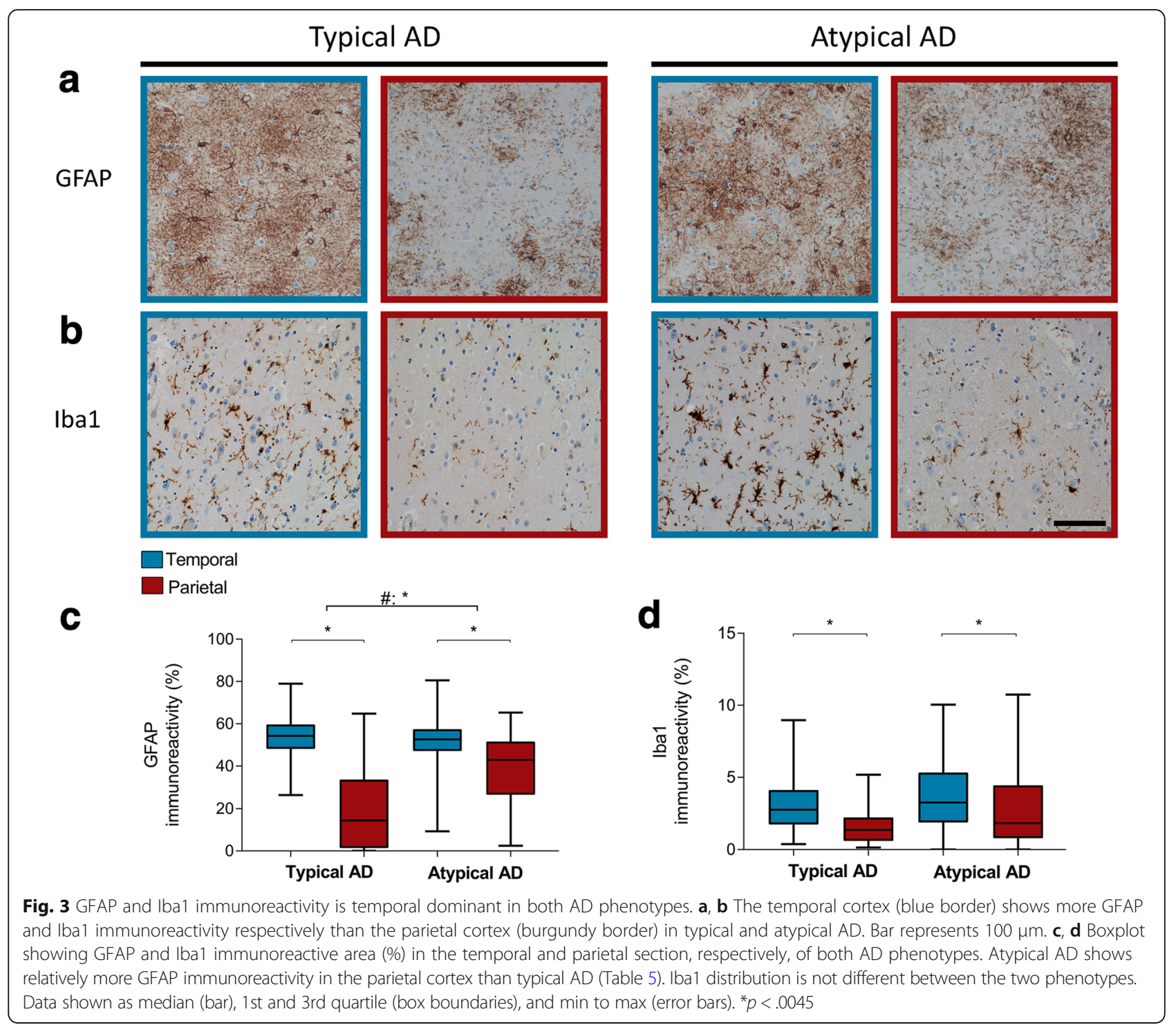

cascade, as well as for C5b-9, defining the end-stage of the cascade and forming the membrane attack complex.

C1q immunoreactivity was observed as a weak diffuse staining in the form of plaque-like structures, as punctuate staining of the neuropil, and sometimes in neurons (Fig. 5a). While the plaque-like structures were more often observed in the parietal section, the punctate staining of the neuropil was more prominent in the temporal section of both $\mathrm{AD}$ groups. No difference in $\mathrm{C} 1 \mathrm{q}$ immunoreactivity was observed between regions or $\mathrm{AD}$ phenotypes (Fig. 5d; Table 5).

Compared to $\mathrm{C} 1 \mathrm{q}$, staining for $\mathrm{C} 3 \mathrm{~d}$ and $\mathrm{C} 4 \mathrm{~b}$ showed an intense plaque-like staining, which had a morphology resembling that of compact and classical cored plaques (Fig. 5b, c). Levels of immunoreactivity for C3d and C4b in typical $\mathrm{AD}$ were higher in the temporal compared to the parietal cortex (Fig. 5e, f; Table 5). In contrast, atypical AD showed higher immunoreactivity levels for both markers in the parietal section compared to the temporal section.

Analysis of C5b-9 exposed very low to no immunoreactivity in both regions of both phenotypes (data not shown). For this reason, no quantification or statistical analysis was performed for C5b-9. The few structures that were C5b-9 positive included parenchymal and meningeal vessels. The serum within these vessels also stained positive for C5b-9.

Our data show a different distribution in temporal and parietal regions between both $\mathrm{AD}$ phenotypes for complement factors C3d and C4b. Both complement factors were mostly abundant in the parietal section of atypical AD. 


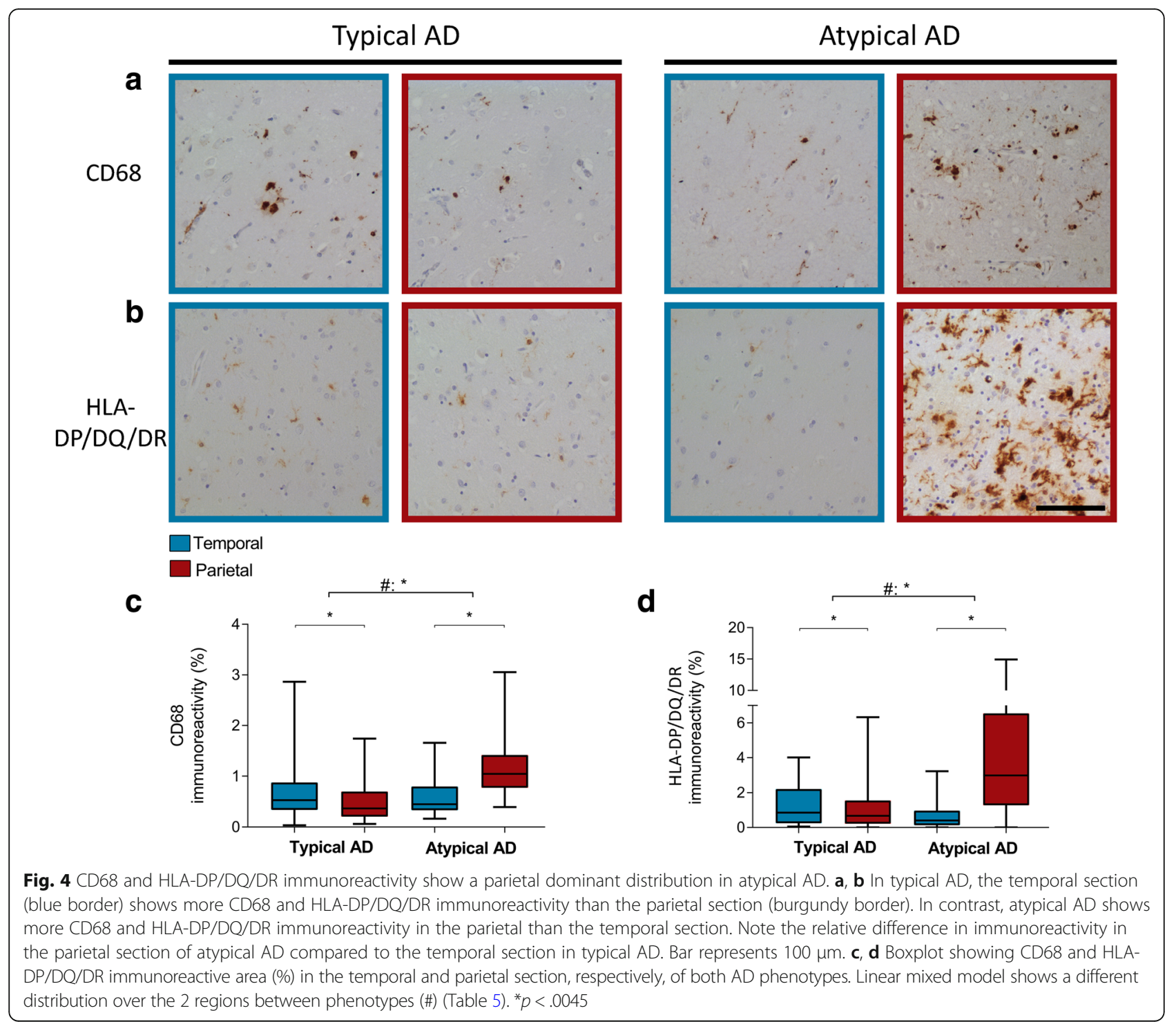

Different plaque appearance in typical and atypical $A D$ Looking at the morphology of plaques stained by amyloid-beta and C4b, we observed a difference in appearance between the $2 \mathrm{AD}$ phenotypes. Amyloid-beta and $\mathrm{C} 4 \mathrm{~b}$ immunoreactive plaques in the parietal section of atypical AD cases showed a more granular composition compared to deposits in the temporal section of this phenotype or compared to deposits in both regions of the typical AD cases (Fig. 6). The surface area positive for $\mathrm{C} 4 \mathrm{~b}$ of these coarse-grained plaques was larger (> $100 \mu^{2}$ ) than that of typical plaques. Atypical AD cases had more of these $\mathrm{C} 4 \mathrm{~b}$ plaques in the parietal compared to the temporal cortex, which was contrary to typical AD cases (Fig. 6i; Table 5). The coarse-grained plaques observed in the parietal cortex of atypical AD triplestained for C4b, amyloid-beta, and thioflavine S (Fig. 7).
This staining pattern was compared with that of classical-cored plaques observed in typical AD. In classical-cored plaques, C4b, amyloid-beta, and thioflavine $\mathrm{S}$ co-localized in the core of the plaque, while the corona only stained for amyloid-beta. Compared to cored plaques, coarse-grained plaques showed a fibrillar, less organized morphology with co-localization of $\mathrm{C} 4 \mathrm{~b}$, amyloid-beta, and thioflavine $\mathrm{S}$ all over the plaque surface. Since an increased presence of activated microglia in atypical $\mathrm{AD}$ was observed, the localization of $\mathrm{CD} 68$ and HLA-DP/DQ/DR with cored and coarse-grained plaques was compared (Fig. 7). Like cored plaques, coarse-grained plaques were associated with clusters of CD68 and HLA-DP/DQ/DR-positive microglia. In cored plaques, activated microglia were located between the core and corona of the plaque. In coarse-grained 


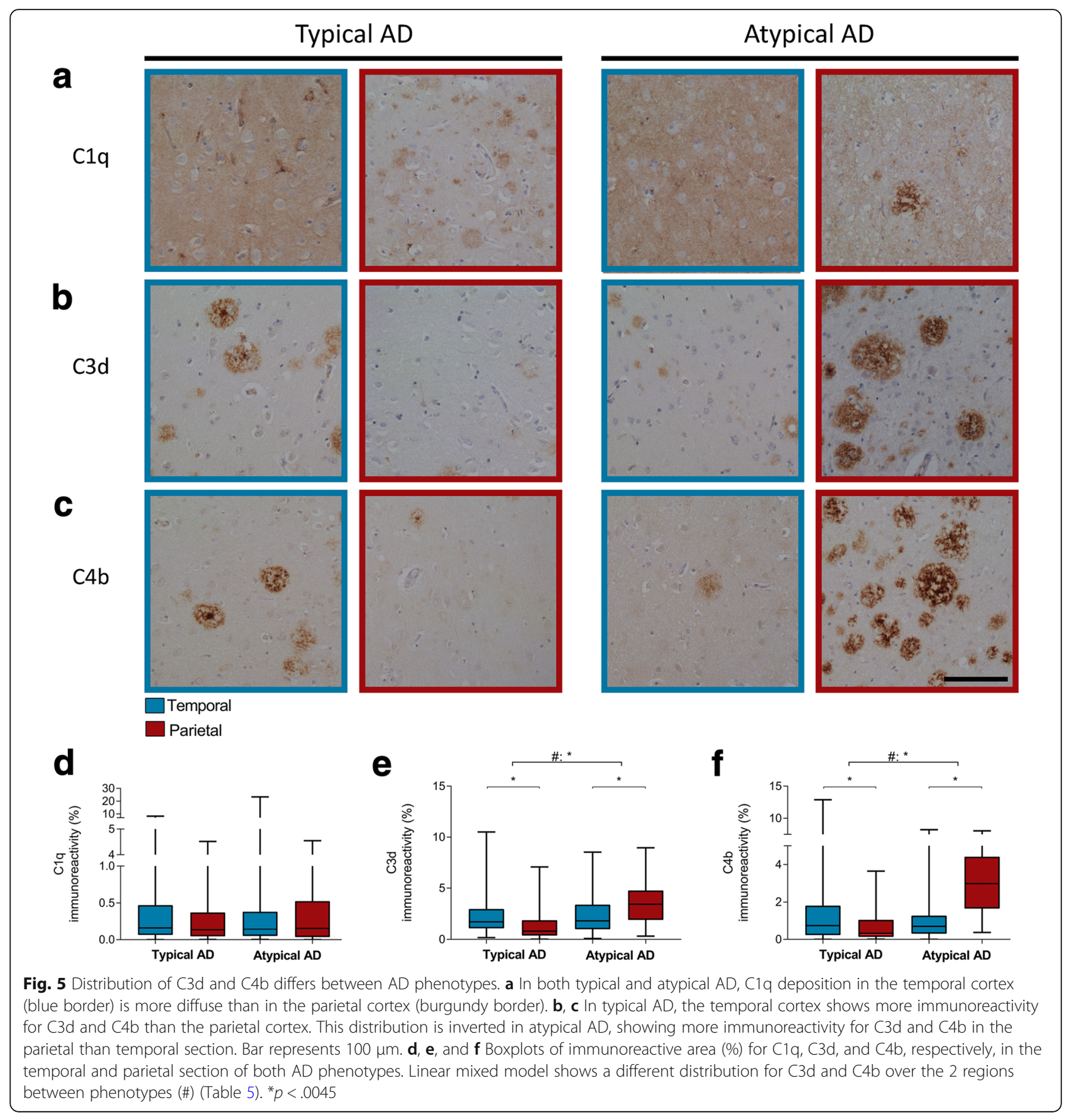

plaques, the localization of CD68 and HLA-DP/DQ/DRpositive microglia was less structured and positive microglia appeared throughout the plaque. This data supports a morphological difference between cored and coarse-grained plaques, of which the latter occurs prominently in atypical AD (Fig. 6i).

\section{Discussion}

Atypical AD is characterized by a different distribution of NFTs when compared with typical AD. As expected, we observed that also the occurrence of pTau is differently distributed in typical and atypical AD. Here, we show for the first time that the distribution of both activated microglia and complement factors between the temporal and parietal lobe differentiates atypical from typical $\mathrm{AD}$ cases. In addition, atypical $\mathrm{AD}$ cases are characterized by the presence of plaques with an abnormal morphology, highlighted by an alternative localization of microglia and presence of complement proteins. 


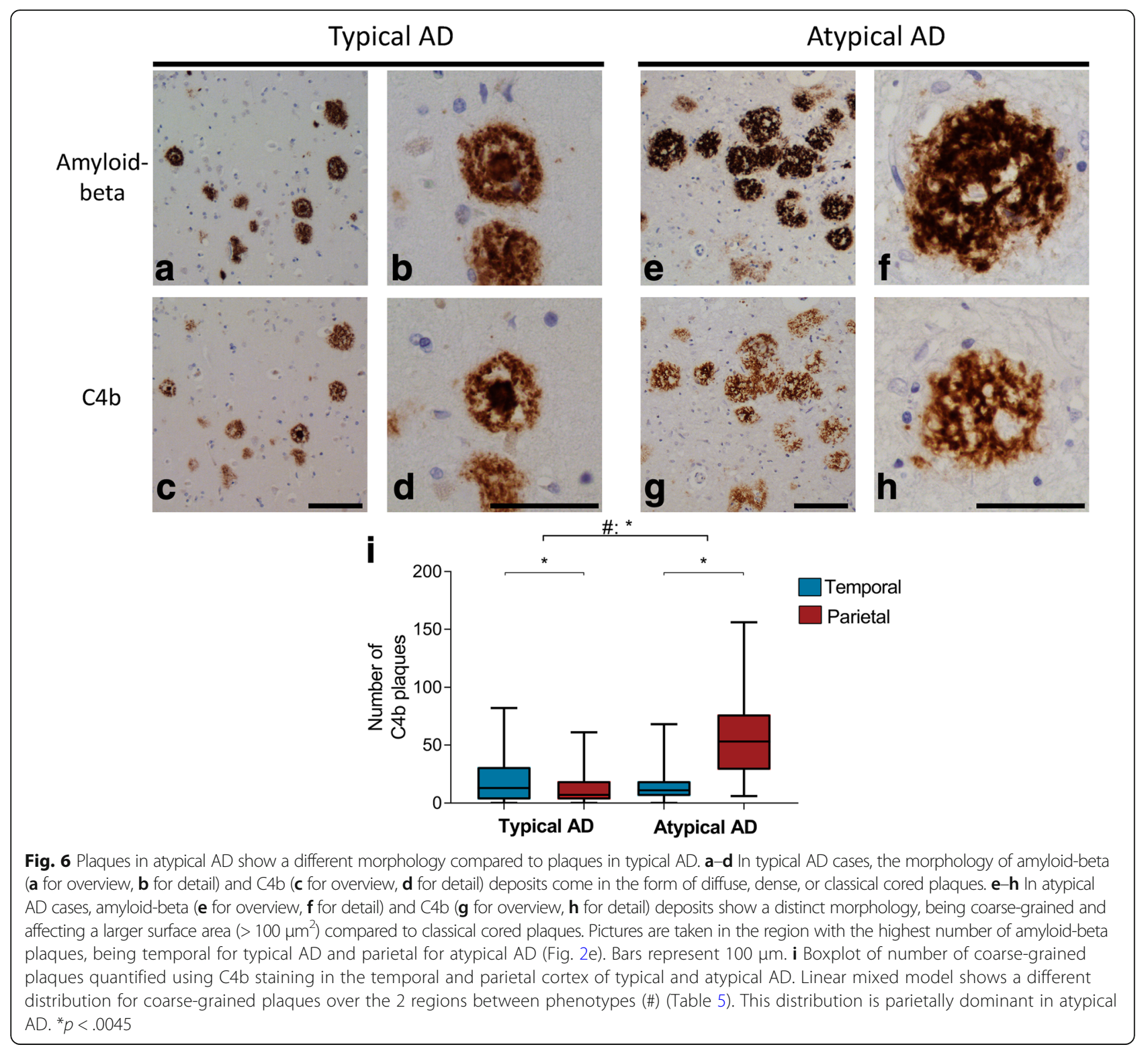

In this study, typical and atypical AD were defined according to the distribution of NFTs as well as their clinical presentation. In our cohort, atypical $\mathrm{AD}$ cases were younger and more often male than typical $A D$ cases. This was also seen in an earlier study by Murray and colleagues [31], indicating that an atypical distribution of pathology seems to be more common in men and at a younger age. In line with this, another study showed that cases with EOAD showed higher mean levels of NFTs in the parietal lobe, when comparing EOAD to LOAD, irrespective of clinical presentation [32]. When taking symptomology into account, this parietal dominant tau distribution is especially common in the PCA variant of atypical AD [11]. Therefore, the current atypical AD cohort defined by parietal dominant NFTs represents only a subgroup of atypical AD. Results from this study do not necessarily apply for patients with a logopenic or behavioral phenotype, as tau pathology seems to be differently distributed in those cases [11, 33]. Besides neuropathological studies, also clinical studies report that an atypical clinical presentation is more common at a younger age [3]. Regarding differences in gender, an atypical presentation is not per se more common in men [3]. However, AD presenting at late-onset is more common in women [34], explaining the relative high number of female subjects in typical AD cohorts.

We did not observe a different distribution of total amyloid-beta immunoreactivity between 2 AD phenotypes. This is in line with other studies reporting that amyloid-beta distribution is not different between $\mathrm{AD}$ subtypes [9, 32, 35-37]. However, when quantifying for number of dense amyloid-beta plaques, atypical AD cases 

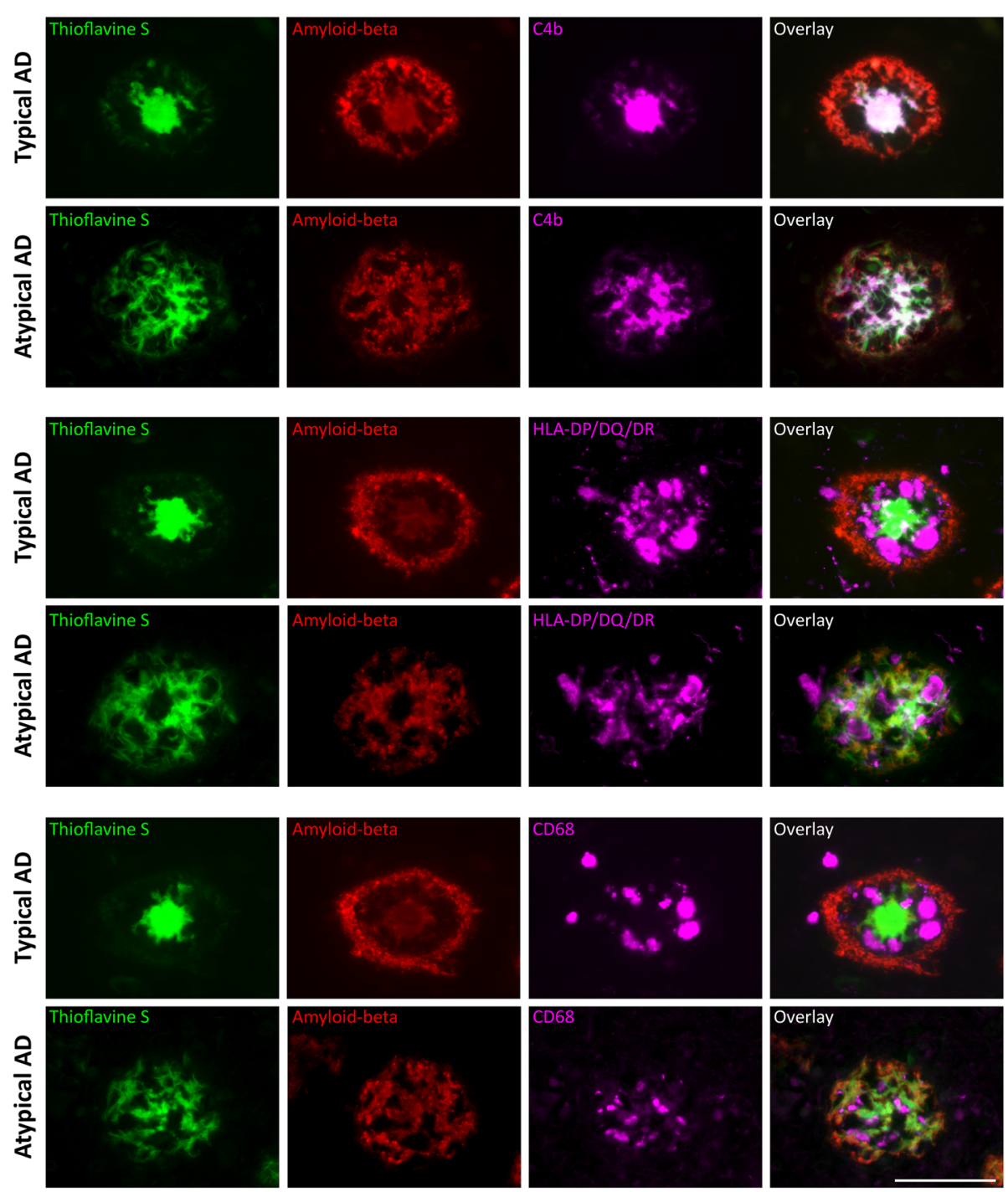

Fig. 7 Different plaque morphology in the parietal cortex of atypical AD. First row: in typical AD, classical cored plaques in the temporal cortex show an organized staining pattern with a corona showing merely amyloid-beta positivity versus a core positive for thioflavine S, amyloid-beta, and C4b. Second row: in atypical AD, fibrillar plaques in the parietal cortex show co-localization of thioflavine S, amyloid-beta, and $\mathrm{C} 4 \mathrm{~b}$ in the form of fibrils throughout the whole plaque. Third row: in typical AD, CD68-positive microglia are localized between the core and corona of classical cored plaques. Fourth row: in atypical AD, CD68-positive microglia localization is less organized. Fifth + sixth row: this different distribution within plaques between the two phenotypes also holds for HLA-DP/DQ/DR-positive microglia. Bar is applicable to all images and represents $100 \mu \mathrm{m}$

showed a parietal dominant distribution compared to typical AD cases, which showed a temporal dominant distribution. This distinction in number of plaques was also reported by Hoff and colleagues who compared cases with PCA to typical AD cases using stereology [38]. These results indicate that although the distribution of overall amyloid-beta immunoreactivity is similar, the number of dense amyloid-beta plaques may differ between AD phenotypes. In addition to the number of dense amyloid-beta plaques, structural differences in amyloid-beta plaques might be associated with the pathological and clinical differences between typical and atypical AD.
In the present study, we observed a clear morphological difference between classical-cored plaques in typical $\mathrm{AD}$ and dense plaques in atypical $\mathrm{AD}$ cases. Dense plaques in atypical AD cases have a coarsegrained structure, as observed with amyloid-beta immunostaining and thioflavine $\mathrm{S}$ staining. In addition, these coarse-grained plaques showed a strong immunoreactivity for complement. Multiple studies have reported complement proteins to be associated with amyloid-beta deposits $[19,39]$. However, a difference in complement activation between AD subtypes has so far not been described. The increased presence of 
complement in coarse-grained plaques in atypical AD cases supports a difference in amyloid structure between typical and atypical AD. Most likely, the amyloid structure of fibrillar plaques favors a strong binding and activation of complement factors, which in turn could act as opsonins for phagocytosis carried out by microglia [17, 40, 41]. A structural variation in amyloid-beta fibrils in combination with a difference in binding of amyloid associated proteins may underlie the observed difference in the occurrence of neuroinflammation, pTau, and NFTs between typical and atypical $\mathrm{AD}$. The relation between amyloid-beta, complement, and microglia is underlined by a study in APP transgenic mice deficient for C3 showing less cognitive problems and more amyloid-beta plaques compared to APP mice not deficient for C3 [42]. The amyloid-beta plaques in the C3 knockout mice showed less microglial co-localization. Together, these findings suggest that structural differences in amyloid deposits in atypical AD may directly be related to complement and microglial activation.

The distribution of NFT and pTau pathology is clearly associated with the presence of activated microglia in AD variants. Recent animal studies have shown that microglia are capable of both internalizing [43] and excreting pTau [24, 44], suggesting that microglia contribute to the spreading of the pathology. Indeed, when mice are depleted for microglia, spreading of tau pathology is significantly reduced [23, 24]. In addition, activated microglia could also contribute or induce tau hyperphosphorylation in neurons [45]. These studies indicate that microglial activation drives the spreading of pathology and stimulates neurofibrillary degeneration. Interestingly, recent evidence from a pathological study suggests that activation of microglia may precede tau pathology in chronic traumatic encephalopathy [46], which implicates that tau pathology may be a consequence rather than a cause for microglial activation.

The aforementioned demographical differences in age and sex may influence the neuroinflammatory response. Former studies have shown various results on the correlation between sex, age, and microglial activation in both humans and animal models. Schwarz et al. showed that during early development, male rats have more microglia within the parietal cortex compared to female rats. However, during juvenile and early adulthood, this balance switches, indicating that sex hormones influence microglial colonization at different time points in rats [47]. In human studies, contradictory results are published for the effect of age. In healthy controls, aging is correlated with a more primed microglial state. Nevertheless, this was shown to be different in diseased cases, in which increasing age is associated with a diminished neuroinflammatory response [25]. These studies suggest that sex and age influence microglia activation. However, whether differences in sex and age contribute to differences in regional distribution, as observed in the current study between $\mathrm{AD}$ subtypes, remain elusive.

\section{Conclusions}

The results of this study are in line with the assumption that the fibrillar structure and protein composition of different plaques may be relevant for the difference in regional vulnerability among AD phenotypes. In addition, our results support a role for activated microglia and complement factors in the atypical spreading of pathology in $\mathrm{AD}$ subtypes. In this study, we focused at 2 brain regions in a subset of atypical $\mathrm{AD}$. It would be interesting to expand this study on the role of neuroinflammation to various brain regions in a larger atypical AD cohort. More clinicopathological studies of AD variants (e.g., logopenic and behavioral frontal) are needed to better understand the relation between amyloid-beta, pTau, and related pathological mechanisms. Future research should focus on how variable disease mechanisms underlie the regional susceptibility in different brain regions leading to different clinical $\mathrm{AD}$ subtypes.

\section{Abbreviations \\ AD: Alzheimer's disease; DAB: 3,3'-Diaminobenzidine tetrahydrochloride; EOAD: Early-onset Alzheimer's disease ( $<65$ years); FFPE: Formalin-fixed paraffin-embedded; GFAP: Glial fibrillary acidic protein; \\ IHC: Immunohistochemistry; IQR: Inter-quartile range; LOAD: Late-onset Alzheimer's disease ( $\geq 65$ years); NBB: Netherlands Brain Bank; NFT: Neurofibrillary tangle; PBS: Phosphate buffer saline; PCA: Posterior cortical atrophy; PMI: Post-mortem interval; pTau: Phosphorylated Tau; ROI: Region of interest}

\section{Acknowledgements}

We would like to thank all brain donors and their caregivers for brain donation, the Netherlands Brain Bank and Michiel Kooreman for logistics and help in selecting brain tissue samples, Martijn Heijmans and Wiesje van der Flier for advice on statistical analysis, Robert Veerhuis for help and advice on complement immunostainings, and Yolande Pijnenburg for clinical assessment.

\section{Funding}

This study was funded by ZonMw grant number 70-73305-98-106. ZonMw had no role in the design of the study, collection, analysis, or interpretation of the data, or writing of the manuscript.

\section{Availability of data and materials}

The datasets used and/or analyzed during the current study are available from the corresponding author on reasonable request.

\section{Authors' contributions}

$\mathrm{FB}$, JJMH, and BDCB designed the study. BDCB and JJMH coordinated the study and were responsible for writing the manuscript. BDCB, BL, and KNE performed the experiments. BDCB analyzed the data. FB participated in writing the manuscript. PS made intellectual contribution and participated in discussions. AJMR, WK, and the NBB were responsible for the autopsy material and neuropathological evaluation. All authors read and approved the final manuscript. 


\section{Ethics approval and consent to participate}

Brain donors signed informed consent for autopsy and the use of tissue and medical records for research purposes. This study was approved by the ethical committee of the VUmc.

\section{Competing interests}

The authors declare that they have no competing interests.

\section{Publisher's Note}

Springer Nature remains neutral with regard to jurisdictional claims in published maps and institutional affiliations.

\section{Received: 19 February 2018 Accepted: 26 April 2018} Published online: 29 May 2018

\section{References}

1. Dubois B, Feldman HH, Jacova C, Hampel H, Molinuevo JL, Blennow K, et al. Advancing research diagnostic criteria for Alzheimer's disease: the IWG-2 criteria. Lancet Neurol. 2014;13:614-29. Available from: http://linkinghub. elsevier.com/retrieve/pii/S1474442214700900. Cited 9 Aug 2017.

2. McKhann GM, Knopman DS, Chertkow H, Hyman BT, Jack CR, Kawas CH, et al. The diagnosis of dementia due to Alzheimer's disease: recommendations from the National Institute on Aging-Alzheimer's Association workgroups on diagnostic guidelines for Alzheimer's disease. Alzheimers Dement. 2011;7:263-9. NIH Public Access. Available from: http://www.ncbi.nlm.nih.gov/pubmed/21514250. Cited 9 Dec 2016.

3. Koedam ELGE, Lauffer $V$, van der Vlies AE, van der Flier WM, Scheltens $P$, Pijnenburg YAL. Early-versus late-onset Alzheimer's disease: more than age alone. J Alzheimers Dis. 2010;19:1401-8. Available from: http://www.ncbi. nlm.nih.gov/pubmed/20061618. Cited 9 Dec 2016.

4. Crutch SJ, Lehmann M, Schott JM, Rabinovici GD, Rossor MN, Fox NC. Posterior cortical atrophy. Lancet Neurol [Internet]. 2012;11:170-8. Available from: http://linkinghub.elsevier.com/retrieve/pii/S1474442211702897. Cited 9 Aug 2017.

5. Gorno-Tempini ML, Hillis AE, Weintraub S, Kertesz A, Mendez M, Cappa SF, et al. Classification of primary progressive aphasia and its variants. Neurology. 2011;76:1006-14. American Academy of Neurology. Available from: http://www.ncbi.nlm.nih.gov/pubmed/21325651. Cited 9 Aug 2017.

6. Ossenkoppele R, Cohn-Sheehy BI, La Joie R, Vogel JW, Möller C, Lehmann $M$, et al. Atrophy patterns in early clinical stages across distinct phenotypes of Alzheimer's disease. Hum Brain Mapp. 2015;36:4421-37. NIH Public Access. Available from: http://www.ncbi.nlm.nih.gov/pubmed/26260856. Cited 29 Dec 2017.

7. Braak H, Braak E. Neuropathological stageing of Alzheimer-related changes Acta Neuropathol. 1991;82:239-59. Available from: http://www.ncbi.nlm.nih. gov/pubmed/1759558.

8. Thal DR, Rüb U, Orantes M, Braak H. Phases of a beta-deposition in the human brain and its relevance for the development of AD. Neurology. 2002 58:1791-800. Available from: http://www.ncbi.nlm.nih.gov/pubmed/ 12084879. Cited 9 Dec 2016.

9. Tang-Wai DF, Graff-Radford NR, Boeve BF, Dickson DW, Parisi JE, Crook R, et al. Clinical, genetic, and neuropathologic characteristics of posterior cortical atrophy. Neurology. 2004;63:1168-74. Available from: http://www.ncbi.nlm.nih.gov/pubmed/15477533. Cited 9 Dec 2016.

10. Galton CJ, Patterson K, Xuereb JH, Hodges JR. Atypical and typical presentations of Alzheimer's disease: a clinical, neuropsychological, neuroimaging and pathological study of 13 cases. Brain. 2000;123 P 3:484-98. Available from: http://www.ncbi.nlm.nih.gov/pubmed/10686172. Cited 9 Dec 2016.

11. Ossenkoppele R, Schonhaut DR, Schöll M, Lockhart SN, Ayakta N, Baker SL, et al. Tau PET patterns mirror clinical and neuroanatomical variability in Alzheimer's disease. Brain. 2016;139:1551-67. Available from: http://www.ncbi.nlm.nih.gov/pubmed/26962052. Cited 9 Dec 2016.

12. Bertram L, Lange $C$, Mullin $K$, Parkinson M, Hsiao M, Hogan MF, et al. Genome-wide association analysis reveals putative Alzheimer's disease susceptibility loci in addition to APOE. Am J Hum Genet. 2008;83:623-32. Elsevier. Available from: http://www.ncbi.nlm.nih.gov/pubmed/18976728. Cited 4 Oct 2017.

13. Naj AC, Jun G, Beecham GW, Wang L-S, Vardarajan BN, Buros J, et al. Common variants at MS4A4/MS4A6E, CD2AP, CD33 and EPHA1 are associated with late-onset Alzheimer's disease. Nat Genet. 2011;43:436-41.
NIH Public Access. Available from: http://www.ncbi.nlm.nih.gov/pubmed/ 21460841. Cited 4 Oct 2017.

14. Hu X, Pickering E, Liu YC, Hall S, Fournier H, Katz E, et al. Meta-analysis for genome-wide association study identifies multiple variants at the BIN1 locus associated with late-onset Alzheimer's disease. PLoS One. 2011;6:e16616. Public Library of Science. Available from: http://www.ncbi.nlm.nih.gov/ pubmed/21390209. Cited 4 Oct 2017.

15. Sims R, van der Lee SJ, Naj AC, Bellenguez C, Badarinarayan N, Jakobsdottir $J$, et al. Rare coding variants in PLCG2, ABI3, and TREM2 implicate microglial-mediated innate immunity in Alzheimer's disease. Nat Genet. 2017;49:1373-84. Available from: http://www.ncbi.nlm.nih.gov/pubmed/ 28714976. Cited 4 Oct 2017.

16. Akiyama H, Barger S, Barnum S, Bradt B, Bauer J, Cole GM, et al. Inflammation and Alzheimer's disease. Neurobiol Aging. 2000;21:383-421. NIH Public Access. Available from: http://www.ncbi.nlm.nih.gov/pubmed/ 10858586. Cited 4 Oct 2017.

17. Shen Y, Yang L, Li R. What does complement do in Alzheimer's disease? Old molecules with new insights. Transl Neurodegener. 2013;2:21. BioMed Central. Available from: http://www.ncbi.nlm.nih.gov/pubmed/24119446. Cited 14 Apr 2017

18. McGeer PL, Akiyama H, Itagaki S, EG MG. Activation of the classical complement pathway in brain tissue of Alzheimer patients. Neurosci Lett. 1989;107:341-6. Available from: http://www.ncbi.nlm.nih.gov/pubmed/ 2559373. Cited 10 Aug 2017.

19. Eikelenboom P, Stam FC. Immunoglobulins and complement factors in senile plaques an immunoperoxidase study. Acta Neuropathol. 1982;57: 239-42. Available from: https://link.springer.com/content/pdf/10.1007/ BF00685397.pdf. Cited 11 Apr 2017

20. Arends YM, Duyckaerts C, Rozemuller JM, Eikelenboom P, Hauw JJ. Microglia, amyloid and dementia in Alzheimer disease. A correlative study. Neurobiol Aging [Internet]. 21:39-47. Available from: http://www.ncbi.nlm. nih.gov/pubmed/10794847. Cited 9 Dec 2016.

21. Dickson DW, Farlo J, Davies P, Crystal H, Fuld P, Yen SH. Alzheimer's disease A double-labeling immunohistochemical study of senile plaques. Am J Pathol. 1988;132:86-101. Available from: http://www.ncbi.nlm.nih.gov/ pubmed/2456021. Cited 9 Dec 2016.

22. Li Y, Liu L, Barger SW, Griffin WST. Interleukin-1 mediates pathological effects of microglia on tau phosphorylation and on synaptophysin synthesis in cortical neurons through a p38-MAPK pathway. J Neurosci. 2003;23:1605-11. NIH Public Access. Available from: http://www.ncbi.nlm. nih.gov/pubmed/12629164. Cited 10 Aug 2017

23. Maphis N, Xu G, Kokiko-Cochran ON, Jiang S, Cardona A, Ransohoff RM, et al. Reactive microglia drive tau pathology and contribute to the spreading of pathological tau in the brain. Brain. 2015;138:1738-55. Oxford University Press. Available from: http://www.ncbi.nlm.nih.gov/pubmed/ 25833819. Cited 9 Dec 2016.

24. Asai H, Ikezu S, Tsunoda S, Medalla M, Luebke J, Haydar T, et al. Depletion of microglia and inhibition of exosome synthesis halt tau propagation. Nat Neurosci. 2015;18:1584-93. NIH Public Access. Available from: http://www.ncbi.nlm.nih.gov/pubmed/26436904. Cited 9 Dec 2016.

25. Hoozemans JJ, Rozemuller AJ, van Haastert ES, Eikelenboom P, van Gool WA. Neuroinflammation in Alzheimer's disease wanes with age. J Neuroinflammation. 2011;8:171. Available from: http://jneuroinflammation. biomedcentral.com/articles/10.1186/1742-2094-8-171. Cited 9 Dec 2016.

26. Mirra SS, Heyman A, McKeel D, Sumi SM, Crain BJ, Brownlee LM, et al. The Consortium to Establish a Registry for Alzheimer's Disease (CERAD). Part II. Standardization of the neuropathologic assessment of Alzheimer's disease. Neurology. 1991;41:479-86. Available from: http://www.ncbi.nlm.nih.gov/ pubmed/2011243. Cited 12 Dec 2016.

27. Hoogendijk WJ, Sommer IE, Pool CW, Kamphorst W, Hofman MA, Eikelenboom P, et al. Lack of association between depression and loss of neurons in the locus coeruleus in Alzheimer disease. Arch Gen Psychiatry. 1999;56:45-51. Available from: http://www.ncbi.nlm.nih.gov/pubmed/ 9892255. Cited 30 Aug 2017.

28. Arendt T, Morawski M, Gärtner U, Fröhlich N, Schulze F, Wohmann N, et al. Inhomogeneous distribution of Alzheimer pathology along the isocortical relief. Are cortical convolutions an Achilles heel of evolution? Brain Pathol [Internet]. 2016; Available from: http://doi.wiley.com/10.1111/bpa.12442. Cited 9 Dec 2016.

29. Walker L, McAleese KE, Johnson M, Khundakar AA, Erskine D, Thomas AJ, et al. Quantitative neuropathology: an update on automated methodologies and 
implications for large scale cohorts. J Neural Transm. 2017;124:671-83. Available from: http://www.ncbi.nIm.nih.gov/pubmed/28265813. Cited 30 Aug 2017.

30. Duyckaerts C, Delatour B, Potier M-C. Classification and basic pathology of Alzheimer disease. Acta Neuropathol. 2009;18:5-36. Available from: http://www.ncbi.nlm.nih.gov/pubmed/19381658. Cited 30 Aug 2017.

31. Murray ME, Graff-Radford NR, Ross OA, Petersen RC, Duara R, Dickson DW. Neuropathologically defined subtypes of Alzheimer's disease with distinct clinical characteristics: a retrospective study. Lancet Neurol. 2011;10:785-96. Available from: http:/www.ncbi.nlm.nih.gov/pubmed/21802369. Cited 9 Dec 2016.

32. Bigio EH, Hynan LS, Sontag E, Satumtira S, White CL. Synapse loss is greater in presenile than senile onset Alzheimer disease: implications for the cognitive reserve hypothesis. Neuropathol Appl Neurobiol. 2002;28:218-27. Blackwell Science Ltd. available from: http://doi.wiley.com/10.1046/j.13652990.2002.00385.x. Cited 26 Oct 2017.

33. Josephs KA, Dickson DW, Murray ME, Senjem ML, Parisi JE, Petersen RC, et al. Quantitative neurofibrillary tangle density and brain volumetric MRI analyses in Alzheimer's disease presenting as logopenic progressive aphasia. Brain Lang. 2013;127:127-34. NIH Public Access. Available from: http://www.ncbinlm.nih.gov/pubmed/23541297. Cited 27 Mar 2018.

34. Snyder HM, Asthana S, Bain L, Brinton R, Craft S, Dubal DB, et al. Sex biology contributions to vulnerability to Alzheimer's disease: a think tank convened by the Women's Alzheimer's Research Initiative. Alzheimers Dement. 2016; 12:1186-96. Available from: http://linkinghub.elsevier.com/retrieve/pii/ S1552526016328746. Cited 14 Apr 2017.

35. Beaufils E, Ribeiro MJ, Vierron E, Vercouillie J, Dufour-Rainfray D, Cottier J-P, et al. The pattern of brain amyloid load in posterior cortical atrophy using (18)F-AV45: is amyloid the principal actor in the disease? Dement Geriatr Cogn Dis Extra. 2014;4:431-41. Karger Publishers. Available from: http://www.ncbi.nlm.nih.gov/pubmed/25538727. Cited 12 Apr 2017.

36. Wang X-D, Lu H, Shi Z, Cai L, Liu S, Liu S, et al. A pilot study on clinical and neuroimaging characteristics of Chinese posterior cortical atrophy: comparison with typical Alzheimer's disease. PLoS One. 2015;10:e0134956. Public Library of Science, Available from: http://www.ncbi.nlm.nih.gov/ pubmed/26267071. Cited 15 Dec 2016.

37. de Souza LC, Corlier F, Habert M-O, Uspenskaya O, Maroy R, Lamari F, et al. Similar amyloid- burden in posterior cortical atrophy and Alzheimer's disease. Brain. 2011;134:2036-43. Available from: https://www.ncbi.nlm.nih. gov/pubmed/?term $=$ de+Souza $+\mathrm{LC} \% 2 \mathrm{C}+$ Corlier+F\%2C+Habert+M-O\%2C. Cited 2016 Dec 9.

38. Hof PR, Vogt BA, Bouras C, Morrison JH. Atypical form of Alzheimer's disease with prominent posterior cortical atrophy: a review of lesion distribution and circuit disconnection in cortical visual pathways. Vis Res. 1997;37:360925. Available from: http://www.sciencedirect.com.vu-nl.idm.oclc.org/science/ article/pii/S0042698996002404. Cited 12 Apr 2017.

39. Zanjani H, Finch CE, Kemper C, Atkinson J, McKeel D, Morris JC, et al. Complement activation in very early Alzheimer disease. Alzheimer Dis Assoc Disord [Internet]. 19:55-66. Available from: http://www.ncbi.nlm.nih.gov/ pubmed/15942322. Cited 14 Apr 2017.

40. Wyss-Coray T, Yan F, Lin AH-T, Lambris JD, Alexander JJ, Quigg RJ, et al. Prominent neurodegeneration and increased plaque formation in complement-inhibited Alzheimer's mice. Proc Natl Acad Sci U S A. 2002;99: 10837-42. Available from: http://www.pnas.org/cgi/doi/10.1073/pnas. 162350199. Cited 14 Apr 2017.

41. Maier M, Peng Y, Jiang L, Seabrook TJ, Carroll MC, Lemere CA. Complement C3 deficiency leads to accelerated amyloid beta plaque deposition and neurodegeneration and modulation of the microglia/macrophage phenotype in amyloid precursor protein transgenic mice. J Neurosci. 2008; 28:6333-41. NIH Public Access. Available from: http://www.ncbi.nlm.nih.gov/ pubmed/18562603. Cited 14 Apr 2017.

42. Shi Q, Chowdhury S, Ma R, Le KX, Hong S, Caldarone BJ, et al. Complement C3 deficiency protects against neurodegeneration in aged plaque-rich APP/ PS1 mice. Sci Transl Med. 2017;9:eaaf6295. Available from: http://www.ncbi. nIm.nih.gov/pubmed/28566429. Cited 30 Aug 2017.

43. Luo W, Liu W, Hu X, Hanna M, Caravaca A, Paul SM. Microglial internalization and degradation of pathological tau is enhanced by an antitau monoclonal antibody. Sci Rep. 2015:5:11161. Available from: http://www.nature.com/articles/srep11161. Cited 30 Aug 2017.

44. Bolós M, Llorens-Martín M, Jurado-Arjona J, Hernández F, Rábano A, Avila J. Direct evidence of internalization of tau by microglia in vitro and in vivo. J Alzheimers Dis. 2015;50:77-87. Available from: http://www.medra.org/
servlet/aliasResolver?alias=iospress\&doi=10.3233/JAD-150704. Cited 11 Apr 2017.

45. Bhaskar K, Konerth M, Kokiko-Cochran ON, Cardona A, Ransohoff RM, Lamb BT. Regulation of tau pathology by the microglial fractalkine receptor. Neuron. 2010;68:19-31. NIH Public Access. Available from: http://www.ncbi. nlm.nih.gov/pubmed/20920788. Cited 20 Dec 2017.

46. Cherry JD, Tripodis Y, Alvarez VE, Huber B, Kiernan PT, Daneshvar DH, et al. Microglial neuroinflammation contributes to tau accumulation in chronic traumatic encephalopathy. Acta Neuropathol Commun. 2016;4:112. Available from: http://actaneurocomms.biomedcentral.com/articles/10.1186/ s40478-016-0382-8. Cited 30 Aug 2017.

47. Schwarz JM, Sholar PW, Bilbo SD. Sex differences in microglial colonization of the developing rat brain. J Neurochem. 2012;120:948-63. NIH Public Access. Available from: http://www.ncbi.nlm.nih.gov/pubmed/22182318. Cited 27 Mar 2018.

\section{Ready to submit your research? Choose BMC and benefit from:}

- fast, convenient online submission

- thorough peer review by experienced researchers in your field

- rapid publication on acceptance

- support for research data, including large and complex data types

- gold Open Access which fosters wider collaboration and increased citations

- maximum visibility for your research: over $100 \mathrm{M}$ website views per year

At $B M C$, research is always in progress.

Learn more biomedcentral.com/submissions 